\title{
Kojève y Deleuze: antropología y ontología en el absoluto hegeliano
}

\section{Kojève and Deleuze: anthropology and ontology in Hegel's absolute}

\author{
JULIÁN FERREYRA
}

$U B A$ / Conicet

Recibido: 30-09-2010 Aprobado definitivamente: 11-11-2010

\begin{abstract}
RESUMEN
El artículo se propone estudiar el rol de la apropiación de Hegel en la filosofía política francesa del siglo XX. Analizaremos de qué manera el énfasis de Kojève en la antropología, de Hyppolite en la ontología y de Weil en la teoría del Estado, implican diferentes visiones de la relación entre metafísica, naturaleza humana y organización política. Y a partir de allí, intentaremos proponer una nueva lectura de Hegel, recurriendo a la matriz interpretativa de Deleuze (a pesar su habitual encuadre como anti-hegeliano).
\end{abstract}

PALABRAS CLAVE

ANTROPOLOGÍA FILOSÓFICA, ONTOLOGÍA, ESTADO, IDEA.

\section{ABSTRACT}

This article aims to study the role of Hegel's appropriation in the French political philosophy of the XX century. We will analyze in which manner the emphasis of Kojève in anthropology, of Hyppolite in ontology and of Weil in the theory of State, imply different visions of the relationship between metaphysics, human nature and political organization. On that basis, we will propose a new reading of Hegel, through the interpretative matrix of Deleuze (even though he is usually regarded as anti-Hegelian).

\section{KEYWORDS}

PHILOSOPHICAL ANTHROPOLOGY, ONTOLOGY, STATE, IDEA. 
Independientemente de lo que piense de ello Hegel, la Fenomenología es una antropología filosófica.

(A. Kojêve)

El saber absoluto no es una antropología (alcanza leer la Lógica de Hegel para darse cuenta).

(J. Hyppolite)

La sucesiva ReApropiación del PEnSAMiento de G. W. F. Hegel es una de las encrucijadas decisivas para el destino de la filosofía política, la posibilidad de que la filosofía sea política, de que la política pueda ser filosófica, más allá de la doxa del ágora mediática y la epistème de la racionalidad moderna aplicada a las desventuras del ser común. En las páginas que siguen estudiaremos un escenario específico para dicha disputa: la recepción de Hegel en Francia. Entre 1933 y 1968, la deriva de la interpretación de Alexandre Kojève de las últimas páginas de la Fenomenología del espíritu en términos de fin de la historia lo conduce desde el trazo de un cuadro bucólico de la humanidad libre de guerra y conflicto hacia el cínico paisaje del American way of life y el snobismo japonés: el contexto de un capitalismo aparentemente triunfador, donde los hombres son meros pobres diablos luchando por sus pellejos. Intentaremos mostrar que tal deriva es consecuencia de su interpretación de la Fenomenología en clave de una reflexión sobre el hombre heredera de una corriente disciplinaria de la década del 1920 en Alemania: la antropología filosófica. Las aporías de tal genealogía desembocarán en el giro abierto por Weil e Hyppolite en la década del '50 hacia un desplazamiento del acento hacia el hombre como reflejo del Estado y la ontología (respectivamente). Es a partir de ese giro que intentaremos introducir en un debate, tal hegeliano y humanista, a un anti-hegeliano y antihumanista como Gilles Deleuze para, a partir de su concepción de la bêtise como «animalidad propiamente humana», plantear una nueva posibilidad de apropiar a Hegel para un estadio más alto (höheren Stufe) de la organización social que supere al capitalismo y al Estado. En suma, para pensar la actualidad de una filosofía política.

\section{KoJÈVE Y LA FENOMENOLOGÍA COMO ANTROPOLOGÍA FILOSÓFICA}

Entre enero de 1933 y mayo de 1939, Alexandre Kojève realizó en la Escuela práctica de Altos Estudios de París el monumental esfuerzo de pedagogía filosófica de llevar a cabo una lectura comentada completa de la Fenomenología del espíritu de Hegel. Estas lecciones, luego publicadas en 1947 a partir de las notas de Raymond Queneau como la Introduction à la lecture de Hegel, marca- 
rían a la generación que vivió y pensó en Francia en la segunda mitad del siglo XX. La segunda edición de 1968 tiene una única adición: apenas dos carillas en forma de nota. Pero en esas carillas podemos encontrar una visión lúgubre, embebida de cinismo, del devenir del hombre y del desenlace de la historia de la humanidad. Veremos cómo sus famosas tesis acerca del fin de la historia sufren una serie de mutaciones a lo largo de los años: de mera constatación a evaluación optimista, para desembocar en el mencionado desencanto cínico. Mi hipótesis de lectura es que ese lúgubre final estaba de alguna manera ya determinado por la interpretación que Kojève había sostenido desde la primera clase: que la Fenomenología es una antropología filosófica. En efecto, en la clase inicial del primer año del seminario (1933), señala Kojève:

Independientemente de lo que piense de ello Hegel, la Fenomenología es una antropología filosófica. Su tema, es el hombre en tanto humano, el ser real en la historia... Esta antropología no es entonces ni una psicología, ni una ontología. Quiere describir la «esencia» integral del hombre, es decir todas las «posibilidades» humanas. ${ }^{1}$

Cuando Kojève dice que la Fenomenología del espíritu es una antropología filosófica, no quiere decir simplemente que ese libro es una reflexión filosófica acerca del hombre. En sentido estricto, está haciendo referencia a la «antropología filosófica» como disciplina surgida en Alemania en la década del '20. Tal disciplina se había estructurado en torno a un corpus de textos preciso: $E l$ enigma de la humanidad de Paul Alsberg (1922), El puesto del hombre en el cosmos de Max Scheler (1928) y El hombre y las etapas de lo inorgánico de Helmuth Plessner (1928). ${ }^{2}$ Dicho corpus implica una concepción específica acerca del hombre, que llevaría a Martin Heidegger en 1929 a atacar duramente la naciente disciplina en Kant y el problema de la metafísica: «La idea de una antropología filosófica no solamente carece de determinación suficiente, sino que su función en el conjunto de la filosofía queda oscura e indecisa». ${ }^{3}$

En 1993, Kojève afirma: «La Fenomenología es una antropología filosófica». Hace así referencia implícita a aquel debate, y toma una posición cercana a Scheler y Plessner y distanciándose de Heidegger precisamente por razones

1 A. Kojève, Introduction à la lecture de Hegel, Paris: Gallimard, 1947 (segunda edición, 1968), p. 39.

2 Para un análisis del surgimiento de la antropología filosófica en Alemania, $c f$. J. Fischer, «Exploring the Core Identity of Philosophical Anthropology through the Works of Max Scheler, Helmuth Plessner, and Arnold Gehlen», Iris, I (2009), Firenze Univesity Press, pp. 153-170.

3 M. Heidegger, Kant y el problema de la metafísica, tr. G. Roth, México: Fondo de Cultura Económica, 1954, p. 179. 
de corte antropológico. ${ }^{4}$ Una breve confrontación de las tesis de Kojève con las de Scheler nos muestra la afinidad entre ambos autores. Kojève nos dice que el hombre «en tanto ser humano», en tanto ser real, es su esencia: «Esta antropología no es entonces ni una psicología, ni una ontología. Quiere describir la "esencia" integral del hombre, es decir todas las "posibilidades" humanas»». Esta esencia será el «espíritu» cuya fenomenología describe Hegel. Scheler, por su parte, decía apenas cinco años antes que el principio que «hace del hombre un hombre» es el espíritu. ${ }^{6} \mathrm{Y}$ a esa esencia del hombre (como a todas las esencias) se accede según Scheler a través del acto fundamental del espíritu: la ideación, que no es otra cosa que lo que Husserl piensa como «reducción fenomenológica». ${ }^{7}$ Por su parte, cuando defiende que la Fenomenología de Hegel es una antropología filosófica «independientemente de lo que piense Hegel», Kojève afirma justamente que «el método de Hegel es una abstracción eidética (Husserl)». ${ }^{8}$

En lo que respecta a lo que intento sostener en estas páginas, esta filiación entre la perspectiva de Kojève y la antropología filosófica alemana clásica es especialmente relevante por la contraposición entre la naturaleza y el espíritu como esencia del hombre que ambos sostienen. Dice Kojève que la ontología para la cual la fenomenología sirve de base: «a pesar de lo que de ello pensara Hegel, es una ontología del Hombre ("Espíritu") y no de la naturaleza». ${ }^{9}$ De la misma manera existe en Scheler un antagonismo entre espíritu y vida: «lo que hace del hombre un hombre es un principio que se opone a toda vida en general». ${ }^{10}$ Lo cual se sigue de que para él la esencia del hombre es un espíritu que piensa ideas, intuye esencias y es capaz de amor, bondad, veneración, etc. ${ }^{11}$ mientras que «el proceso de la vida... se realiza exclusivamente por medio de las materias y fuerzas del mundo inorgánico... que son ciegos para las ideas y las formas». ${ }^{12}$

4 «La importancia de lo humano en filosofía puede ser traducida en la obra de Kojève como "la importancia de la historia en la filosofía". Mantiene una distancia crítica de Heidegger porque tal traducción es inapropiada a una lectura coherente de Ser y tiempo y entra en conflicto con temas importantes de los ensayos que lo siguieron», M. Roth, Knowing and History, Appropriations of Hegel in Twentieth-Century France, New York: Cornell University Press, 1988, p. 90

5 A. Kojève, Introduction à la lecture de Hegel, Paris: Gallimard, 1947 (segunda edición, 1968), p. 39. La traducción es mía.

6 Cfr. M. Scheler, El puesto del hombre en el cosmos, tr. J. Gaos, Buenos Aires: Losada, 1938, pp. 60-61.

7 Scheler, op. cit., p. 78.

8 Kojève, op. cit., p. 39.

9 Ibid.

10 Scheler, op. cit., p. 60.

11 Cf. Scheler, op. cit., p. 61.

12 Scheler, op. cit., p. 94. 
Kojève hereda esta contraposición radical entre hombre y vida de la antropología filosófica en contra de lo que piensa Hegel según la interpretación del mismo Kojève (de manera explícita y reiterada: «independientemente de lo que Hegel piense....», «a pesar de lo que de ello pensara Hegel», ${ }_{13}^{13}$ ). Esa influencia del pensamiento que le es contemporáneo lleva al filósofo de origen ruso al callejón sin salida en el que él mismo se encierra, primero sobre el final de su curso (1939) y luego, y en forma más radical, sobre el final de su vida: una visión desesperanzada y cínica del destino de la humanidad en tiempos de capitalismo bajo una concepción donde la historia ha terminado.

En la última clase de sus lecciones sobre Hegel (1939), dedicada a los últimos párrafos de la Fenomenología (parte VIII, «el saber absoluto»), Kojève presenta su tesis célebre: que el saber absoluto exige el abandono de la individualidad y la humanidad: aceptación última de la muerte del hombre. ${ }^{14}$ Esta muerte no le aparece al momento de esa última clase como algo especialmente trágico, sino simplemente como el hecho que «el Hombre se suprime como Error [con mayúscula en el original] (o "Sujeto" opuesto al objeto) después de haber creado la Verdad de la ciencia». ${ }^{15}$ En el saber absoluto, entiende Kojève, el hombre se suprime: se hunde en la noche de la autoconciencia. Todo fue un error. La cuestión es liquidada someramente en esa última clase. Un golpe seco de guillotina, y a la bolsa. Ocurre que las palabras de Kojève coinciden con el inicio de la segunda guerra mundial. La supresión del hombre como error tenía aires de liberación ante la posibilidad nada descabellada en ese momomento de un triunfo de los ejércitos de Hitler. Todo fue un error: erradicado éste será por el advenimiento del saber absoluto.

Pero en 1947, al momento de la primera edición del libro, la cuestión evidentemente se ha vuelto más complejo: Hitler ha sido derrotado y quizás la humanidad no sea un simple error para archivar como baja etapa del desarrollo del espíritu. En una nota agregada para la publicación (que es lo único que en el libro proviene directamente de la pluma de Kojève y no de los apuntes de clase de Queneau) aclara que esta muerte como error «no es tampoco una catástrofe biológica: el Hombre permanece en vida en tanto animal que está en acuerdo con la Naturaleza o el Ser dado». ${ }^{16}$

Lo que desaparece, es el hombre propiamente dicho, es decir la acción negadora de lo dado y el Error, o en general el Sujeto opuesto al Objeto. De hecho, el fin del Tiempo humano o de la Historia, es decir la aniquilación definitiva del Hombre propiamente dicho o el Individuo libre e histórico, significa simplemente el cese

13 Cf. Kojève, op. cit., p. 39.

14 Cf. Kojève, op. cit., p. 443.

15 Kojève, op. cit., p. 435.

16 Ibid. 
de la Acción en sentido fuerte del término. Lo que quiere decir en la práctica: -la desaparición de las guerras y las revoluciones sangrientas... pero todo lo demás permanece y puede mantenerse indefinidamente; el arte, el amor, el juego, etc. etc.; en suma, todo lo que hace al Hombre feliz. ${ }^{17}$

En 1947 Kojève se enfrenta con un «fin de la historia» que, como en 1939, no aparece como trágico, pero cuya ausencia de tragedia se ve en necesidad de precisar. La guerra ha terminado, Hitler ha sido vencido, y ya no es cuestión de la supresión del hombre tout court. Precisa entonces Kojève que se trata «de la desaparición de las guerras y revoluciones sangrientas». Esas son ahora las prioridades. La sangre está aún fresca, y se trata de vestir al fin de la historia con las ropas de la paz perpetua.

Pero junto con esas promesas de paz, arte, amor y juego indefinidos, la nota aclaratoria introduce un conflicto interno a su planteo. Porque si el hombre «permanece en vida en tanto animal», entonces la existencia del hombre en la post-historia no es otra cosa que vida sin más, lo que Agamben, en torno a una cuestión que no es totalmente ajena a lo que aquí tratamos pero que no podemos abordar en estas páginas, llamaría nuda vida ${ }^{18}$ Esa vida sin más que permanecería tras la supresión del hombre en el fin de la historia («materias y fuerzas del mundo inorgánico, ciegas para las ideas y las formas», había dicho Scheler) tiene las características de lo que Hegel llamó «naturaleza orgánica», y cuya propiedad es la de ser un mero movimiento contingente:

La naturaleza orgánica no tiene historia alguna; desde su universal, que es la vida, desciende inmediatamente a la singularidad del ser allí (Dasein), y los momentos unidos de esta realidad, los momentos de la simple determinabilidad y de la vitalidad singular, producen el devenir solamente como el movimiento contingente en el que cada uno de ambos momentos es activo en la parte que le toca y el todo se mantiene. ${ }^{19}$

17 Ibid.

18 De hecho en Lo abierto, Giorgio Agamben, liga explícitamente la problemática en las últimas páginas del Introducción a la lectura de Hegel, con el problema de la nuda vida y la biopolítica anunciado en Homo sacer: «Kojève privilegia el aspecto de la negación y de la muerte, y parece no ver el proceso por el cual, en la modernidad, el hombre (o el Estado, para él) comienza en cambio a ocuparse de la propia vida animal, y la vida natural se convierte, sobre todo, en lo que está en juego en aquello que Foucault llamó el biopoder. Tal vez, el cuerpo del animal antropóforo (el cuerpo del siervo) es el resto no resuelto que el idealismo deja en herencia al pensamiento, y las aporías de la filosofía en nuestro tiempo coinciden con las aporías de este cuerpo irremediablemente tenso y dividido entre animalidad y humanidad», G. Agamben, $L o$ abierto, tr. F. Costa y E. Castro, Buenos Aires: Adriana Hidalgo, 2006, p. 28.

19 G. W. F. Hegel, Fenomenología del espíritu, tr. W. Roces, México: Fondo de Cultura, 1966, p. 179 (Phänomenologie des Geistes, Hamburg: Meiner, 1988, p. 199). 
Resuena la bella frase formulada sólo algunas páginas antes: «Es ist diesem Strome des Lebens gleichgültig, welcher Art die Mühlen sind, die er treibt [a este río de la vida le es indiferente de qué especie sean los molinos que sus aguas impulsan]». ${ }^{20}$ Lo que la vida encuentra, lo impulsa, indiferente. Cada momento es indiferente al otro. La contingencia es la ley. Cada uno actúa por su parte, independiente, aislado (jedes an seinem Teile tätig ist). Ciego es el río de la vida a la Idea, a las articulaciones conceptuales del mundo humano en su estadio más evolucionado.

Ocurre que la «naturaleza orgánica» ocupa en el desarrollo de la Fenomenología un estadio marcadamente anterior al saber absoluto. Aparece en la sección «Razón, observación de la naturaleza», donde Hegel efectivamente trabaja la especificidad «biológica» del hombre. El sistema hegeliano está construido en estadios o fases (Stufen), literalmente, «escalones» o «peldaños», que conforman una suerte de escalera de Escher donde el entramado de evolución constante no lleva a una «mala infinitud» sino que componen un círculo «que sólo es real por medio de su desarrollo». ${ }^{21}$ Se trata de un proceso de continuo desarrollo, donde nunca se desciende hacia niveles previos. Es sumamente curiosa la interpretación de Kojève según la cual el Espíritu, al llegar a la cúspide de su desarrollo, recaería en un estadio tan primitivo como el de la naturaleza orgánica. El fin de la historia acarrearía según Kojève el fin de la organización de la sociedad humana de acuerdo al concepto, un retroceso no sólo hacia etapas previas al Estado, sino incluso más allá de la sociedad civil, hacia una naturalidad donde cada individuo post-humano es una existencia empírica (como traduce Kojève «Dasein») librada al ciego río de la vida.

\section{EL HOMBRE SE SUPRIME COMO ERROR}

Las últimas páginas de la Fenomenología del espíritu son pasaje especialmente oscuro y ha despertado amplias controversias a nivel de la interpretación «definitiva» de G. W. F. Hegel: «este pasaje de la historia al saber absoluto, pasaje de lo temporal a lo eterno, es la síntesis dialéctica más oscura del hegelianismo». ${ }^{22}$ Cuando Kojève lee allí la supresión del hombre, el fragmento que está analizando (recordemos que la metodología del seminario es la lectura de un fragmento de la Fenomenología y su análisis) es el siguiente:

20 Hegel, Fenomenología..., op. cit., p. 172, traducción modificada (Phänomenologie, op. cit., p. 191).

21 «[Lo verdadero] es el devenir de sí mismo, el círculo que presupone y tiene por comienzo su término como su fin y que sólo es real por medio de su desarrollo y su fin», Hegel, Fenomenología..., op. cit., p. 16 (Phänomenologie.., op. cit., p. 14).

22 J. Hyppolite, Logique et existence, Paris: PUF, 1952, p. 247. La traducción es mía. 
Este último devenir del espíritu, la naturaleza, es su devenir vivo e inmediato; la naturaleza, el espíritu enajenado [entaußerte Geist], no es en su ser allí [Dasein, existence-empirique] otra cosa que esta eterna enajenación de su subsistencia y el movimiento que instaura al sujeto. Pero el otro lado de su devenir, la historia, es el devenir que sabe, el devenir que se mediatiza a sí mismo -el espíritu enajenado en el tiempo [die Zeit entäußerte Geist]; pero esta enajenación es también la enajenación de ella misma; lo negativo es lo negativo de sí mismo. ${ }^{23}$

Kojève entiende a partir de aquí que, hacia el final de la Fenomenología, «el hombre y la historia alcanzan su fin», ${ }^{24}$ y se suprimen dando lugar a la naturaleza. El argumento de Kojève implica dos momentos: uno, que la enajenación del espíritu en el tiempo (como historia) era una negación que, al negarse nuevamente («lo negativo es lo negativo de sí mismo»), acarrea una supresión del hombre y de la historia; es decir, que lo "negativo de lo negativo" es una supresión sin conservación (y no es por lo tanto la Aufheben característica del movimiento hegeliano ${ }^{25}$ ). Segundo, que esa supresión se realiza «en provecho de la naturaleza». Estos dos momentos están atados por los presupuestos implícitos de la antropología filosófica con los cuales Kojève trabaja, y que lo hacen leer a Hegel a contrapelo de sus premisas fundamentales.

En efecto, la interpretación de Kojève está teñida por la radical oposición entre espíritu y vida que hereda de la corriente de Scheler. Pareciera que el filósofo ruso está denunciando ese presupuesto cuando dice que «el hombre se suprime en tanto Error (o Sujeto opuesto al Objeto)»». ${ }^{26}$ El enfrentamiento vida-espíritu sería precisamente el error que se trata de suprimir. Podría pensarse que así supera Kojève las ilusiones de la antropología filosófica. Pero lejos de ello, esa forma de razonar lo lleva a profundizar en dichas ilusiones. El hombre es un error en tanto es pensado como sujeto. ${ }^{27}$ Pero justamente como no puede pensarse sino como

23 Hegel, Fenomenología...op. cit., p. 472. Entre corchetes señalamos en francés la traducción de Kojève (op. cit., p. 434) y en alemán los términos originales ( $c f$. Phänomenologie... op. cit., p. 530).

24 Kojève, op. cit., p. 432. «Cuando el error específicamente humano es finalmente transformado en verdad de la ciencia absoluta, el Hombre deja de existir en tanto Hombre y la Historia alcanza su fin. La supresión del Hombre (es decir del Tiempo, es decir de la Acción) en provecho de un Ser-estático (es decir del Espacio, es decir de la Naturaleza) es entonces la supresión del Error en provecho de la Verdad», ibid.

25 «La superación [Aufheben] presenta su verdadera doble significación, que hemos visto en lo negativo: es al mismo tiempo un negar y un mantener [Aufbewahren]», Hegel, Fenomenología, op. cit., p. 72 (Phänomenologie... op. cit., p. 80).

26 Kojève, op. cit., p. 435.

27 «Si se toma al hombre como aquel ente que... es sencillamente lo primero y más cierto, una filosofía, concebida y planeada en tal forma, tiene que asignar a la subjetivdad humana una importancia central», Heidegger, op. cit., p. 179. 
sujeto, al suprimir el hombre como sujeto se suprime la esencia del hombre, y lo que subsiste ya no es propiamente un hombre. Lo que nunca se suprime es la concepción antropológica (que el hombre es su esencia y ésta un espíritu).

La única desventura del pensamiento que Kojève reconoce es el error. ${ }^{28}$ El error es solamente el negativo de la verdad, un desvío del buen sentido, que debe reencontrarse con su verdad que subsiste con total independencia del error. El error debe simplemente suprimirse para reencontrar una verdad que había sido perdida solamente por el pensamiento que había errado. Se suprime y su opuesto subsiste, independiente. Por lo tanto, es lógico que si el hombre es un error, al suprimirlo, su opuesto subsista: ¿cuál es ese opuesto? La vida, la naturaleza ciega. El error y el negativo de oposición muestran su codependencia. Y esto porque la antropología filosófica en la que basa Kojève su concepción del hombre se inserta plenamente en la imagen dogmática del pensamiento. Siempre concebido como sujeto y error: la apología y la disolución del hombre tienen la suerte ligada en una misma ilusión antropológica.

Sin embargo, nada en Hegel sostiene la interpretación de Kojève que de esa supresión del hombre se siga la subsistencia de la vida como entramado de fuerzas independientes. La afirmación de Hegel que la naturaleza «no es en su existencia otra cosa que esta eterna enajenación de su subsistencia» es interpretada por Kojève en forma transparente como subsistencia eterna efectiva de la naturaleza orgánica; pero esto sólo merced a una premisa adicional: la perspectiva de la antropología filosófica que opone naturaleza y espíritu.

\section{UN ANIMAL SNOB, O EL TRIUNFO DEL CAPITALISMO}

Inmediatamente a continuación del fragmento en el cual Kojève basa su interpretación de la «supresión del hombre y de la historia», Hegel continúa con consideraciones que Kojève lee en su curso pero sin darles ningún peso argumentativo particular:

Es el nuevo ser allí [Dasein], un nuevo mundo y una nueva figura del espíritu. En él, el espíritu tiene que comenzar de nuevo desde el principio... Si este espíritu reinicia desde el comienzo su formación, pareciendo solamente partir de sí mismo, comienza al mismo tiempo por una etapa más alta. ${ }^{29}$

28 Queda así preso de lo que Deleuze llama «la imagen dogmática del pensamiento» que «no reconoce más que el error como desventura del pensamiento». Veremos más adelante la propuesta de Deleuze de pensar el hombre no como "error" sino como "bêtise". Cf. G. Deleuze, Différence et répétition, Paris : PUF, 1968, p. 192. La traducción es mía.

29 Hegel, Fenomenología, op. cit., p. 473. «So ist es zugleich auf einer höheren Stufe, dass er anfängt» Phänomenologie... op. cit., p. 530. 
Justamente hacia allí queremos desplazar el acento. Estamos en las últimas líneas de la Fenomenología... y por tanto Hegel no dice qué esperar de esta «etapa más alta». Pero vale pensar que no se trata de transformarnos nuevamente en meros animales chapoteando en el río de la vida, librados a la contingencia de los encuentros en la existencia (etapa sin duda más baja). Se podría pensar que la «etapa más alta» a la que hace referencia aquí fue concebida en vida por el propio Hegel, y tomó en su obra de madurez la forma del Estado, que Hegel contrapone en sus Principios de la filosofía del derecho (1821) explícitamente a la naturaleza:

El Estado es el mundo que se ha dado el espíritu; por ello tiene una marcha determinada, existente en y por sí. Con cuánta frecuencia se habla de la sabiduría de Dios en la naturaleza; pero no debe creerse que el mundo físico material sea algo más elevado que el mundo del espíritu, pues tan por encima como está el espíritu respecto de la naturaleza lo está el Estado respecto de la vida física. ${ }^{30}$

Los términos son los mismos que en 1807: Natur, Geist, Höher. El espíritu es un estadio más alto que la naturaleza, y en la misma medida el Estado respecto de la vida física («so hoch der Geist über der Natur steht, so hoch steht der Staat Über dem physischen Leben»). Concluido el ciclo del saber, no nos encontramos con animales chapoteando en el río de la vida, sino con un nuevo ciclo, cuyo estadio más elevado es el Estado, y al cual Hegel dedica su obra de 1821. Esta condición más elevada del Estado respecto a la vida física en el texto hegeliano no le es evidentemente desconocida a un especialista como Kojève, que es plenamente conciencie del estado pre-Estatal del hombre librado a la nuda vida. En el curso de los años 34-35, dedicado justamente a la razón observante, señalaba:

La historia no existe fuera de los individuos que la hacen, la Tierra por el contrario y los individuos biológicos no existen sobre el mismo plano. La naturaleza orgánica no tiene entonces historia; cae directamente del universal en lo particular: de la Vida en general a esta planta, este animal. El hombre difiere del animal, porque es Ciudadano (Bürger); no puede realizarse en tanto hombre más que por intermediario del pueblo (Volk) organizado en Estado (Staat). La Vermittlung [mediación] está en el fondo de la acción en y por la Sociedad... Pero en el mundo

30 G. W. F. Hegel, Principios de la filosofía del derecho, tr. J. L. Vermal, Barcelona: Edhasa, 1999, p. 411. «Man muss aber ja nicht glauben, dass die physische Naturwelt ein Höheres sei als die Welt des Geistes, denn so hoch der Geist über der Natur steht, so hoch steht der Staat Über dem physischen Leben», Hegel, G. W. F. Grundlinien der Philosophie des Rechts, Frankfurt am Main, Suhrkamp, 1970, p. 434. 
puramente natural, vital, no hay Vermittlung (mediación), porque no hay sociedad (Volk, Staat)... Fuera de la sociedad el Hombre no es más que un animal (la «bestia intelectual» [«bête intellectuelle»] del capítulo V, C, a). ${ }^{31}$

Lo dice Kojève mismo: no habiendo organización estatal, estamos librados al ciego río de la vida. ¿Por qué habría entonces de escoger hacia el final de las lecciones esta vía interpretativa en lugar de retomar el devenir hegeliano hacia el Estado $?^{32}$ Podría conjeturarse que en 1939 el Estado le aparece a Kojève como excesivamente ligado a la guerra y el derramamiento de sangre. El Estado no aparece como la etapa «más alta» postulada en la Filosofía del derecho, sino como una etapa aún baja, como en la Fenomenología: «[la conciencia] encuentra en él [el poder del Estado] el obrar, como obrar singular, negado y sometido a obediencia. Ante este poder, el individuo se refleja, pues, en sí mismo; el poder del Estado es para él la esencia opresora y lo malo». ${ }^{33}$ El Estado orgánico de la paz perpetua de la Filosofía del derecho nunca surgió. Las guerras del siglo XX no serían más que la continuación de la dialéctica entre el Estado (Staat) y la Riqueza (Reichtum) planteada en Fenomenología, VI, B, I. En el marco de esa dialéctica, el Estado es "esencia opresora” y lo malo. Quizás mejor volver al estadio más alto de la Fenomenología..., leer sus últimas páginas y buscar allí el fin de la historia y la subsistencia eterna efectiva de la naturaleza orgánica. Suprimir el hombre como error (1939) o, mejor aún, tras el final de la guerra (1947) haber encontrado en el camino del río de la vida finalmente los molinos de la desaparición de las guerras y las revoluciones sangrientas de la historia civil. Si la historia termina aquí, el hombre será feliz.

Desafortunadamente, el desarrollo histórico de la segunda mitad del siglo XX echó por tierra la utopía que Kojève imaginaba en 1947. El desarrollo descarnado del capitalismo ha disuelto la dialéctica entre el Estado (cuya última figura sería el totalitarismo del bloque soviético) y la Riqueza planteada en la Fenomenología VI, B, I a favor de ésta última. En la única modificación introducida en 1968 para la segunda edición del libro, Kojève señala cómo su experiencia en los años que siguieron al '47 le mostró el derrumbe de su utopía:

Numerosos viajes comparativos efectuados (entre 1948 y 1958) a Estados Unidos y la Unión Soviética me han dado la impresión que si los norteamericanos parecen

31 Kojève, op. cit., p. 84.

32 Sobre las tensiones en el pensamiento de Kojève entre el fin de la historia y la concepción de una filosofía política estatalista, $c f$. A. Kojève, «Tiranía y sabiduría», en L. Strauss Sobre la tiranía, seguido del debate Strauss-Kojève, Madrid: Encuentro, 2005, pp. 171-217.

33 Hegel, Fenomenología... op. cit., p. 295 (Phänomenologie... op. cit., p. 330). En esta figura Kojève veía el Estado correspondiente al feudalismo, oponiéndose al desarrollo del espíritu burgués del capitalismo naciente (cf. Kojève, Introduction... op. cit., p. 123). 
sino-soviéticos enriquecidos, es porque los rusos y los chinos no son más que norteamericanos todavía pobres, y por cierto en vías de rápido enriquecimiento. Eso me llevó a concluir que el American way of life era el tipo de vida propio del período post-histórico, la presencia actual de Estados Unidos en el Mundo prefigurando el futuro «eterno presente» de la humanidad entera. El retorno del hombre a la animalidad ya no aparecía como una posibilidad por venir, sino como una certeza presente. ${ }^{34}$

La posthistoria tomó la forma del triunfo del American way of life, es decir, del capitalismo en su forma más desarrollada. En esas condiciones los hombres no eran ya felices, sino pobres diablos luchando por sus pellejos. ${ }^{35}$ Pero der Strome des Lebens fue indiferente al sufrimiento humano generado por su cauce. No es extraño entonces que Kojève señale en esa nota agregada a la segunda edición su propia contradicción: si permanece como animal, el hombre pierde sus artes, sus amores y sus juegos, que deben volverse, ellos también, «naturales». «Un animal que está de acuerdo con la naturaleza o el ser-dado es un ser viviente que no tiene nada de humano», ${ }^{36}$ reconoce. Suprimido el hombre como esencia no queda nada humano: ilusión antropológica. Y plantea la necesidad de buscar una característica que permitiera al hombre «permanecer». La encuentra en la civilización japonesa, en la figura del snob: «una vida en función de valores formalizados, es decir, vaciados de todo contenido humano o sentido histórico»». ${ }^{37}$

34 Kojève, op. cit., pp. 436-437.

35 Tomamos esta expresión de Leo Strauss, cf. Die Religionskritik Spinozas und zugehörige Schriften, Stuttgart: J. B. Metzler, 1996/2001, p. 294.

36 Kojève, op. cit., p. 437.

37 Ibid. Frente a esta «solución» de Kojève al problema planteado por el estado de desesperanza social que acompaña la evolución del capitalismo, Eric Weil planteará la necesidad de volver a pensar el Estado: «Weil modifica entonces la concusión kojéviano-hegeliana de que la historia, propiamente, ha terminado. Está de acuerdo con esta conclusión en la medida en que dice que en principio se puede conocer ahora la dirección, el Final, del progreso histórico. Para Weil, sin embargo, esta posibilidad significa sólo que la historia puede terminar [nota a pie: En Hegel y el Estado, Weil enfatiza que para Hegel, la condición entre los estados no es todavía racional y por lo tanto no es definitiva. De todas maneras, el objetivo de la historia -la condición racional- está a la vista]» (Roth, op. cit., p. 156). Ocurre que ese Estado que «está a la vista» y cuya forma no puede aún decirse, implica el retorno de la guerra y el surgimiento de un «gran hombre»: «Una nueva forma se anuncia. A la filosofía no le corresponde decir cómo será... La curación vendrá, vendrá mediante la realización consciente de la libertad racional, quizás por la obra de un héroe, de un gran hombre, probablemente a través de las guerras, gracias a la obra de las pasiones. Vendrá también por el Estado, por el Estado finalmente realizado, no en el Estado actual sino a través de él; pues si bien es insuficiente, él es y sigue siendo la verdad de la época» (E. Weil, Hegel y el estado, tr. M. T. Pyrazian, Córdoba: Nagelkop, 1070, pp. 130-131). 


\section{De LA REFLEXIÓN SOBRE EL HOMBRE AL HOMBRE COMO REFLEJO DEL ABSOLUTO}

El capitalismo es en efecto la forma actual de nuestra época histórica. Pero quizás no estemos condenados a ser, como mucho, snobs. Quizás el capitalismo no sea el final de la historia, y una nueva forma se anuncie. Y ello no necesariamente implica volver al Estado. La dialéctica Riqueza-Estado está muy presente en el debate político-económico actual en términos de mercado versus estado, o economía versus política; considérense, por ejemplo, las discusiones relativas a la crisis financiera internacional (y las medidas para enfrentarla) o en torno a las causas del renovado desarrollo de América latina (donde economistas ortodoxos y los gobiernos se enfrentan usualmente en contiendas respecto a si es el mercado o el rol del Estado el origen de tal desarrollo). Si se trata de pensar en Hegel la superación de esa dialéctica de la sección "El espíritu extrañado de sí mismo", el final de la Fenomenología debería resolverse a favor de un estadio más alto. Ese Stufe no debería ser entonces ni el Estado ni el Capital. Mucho menos el retorno a la animalidad. Quizás la relectura de ese pasaje tan oscuro de la historia de la filosofía que son las últimas páginas de la Fenomenología nos permita pensar ese más allá, ese höheren Stufe. Continuemos la lectura de Hegel. Luego del pasaje en el cual Kojève se apoyaba para postular la muerte del hombre y la historia, y luego de aquel que nos permitió pensar un estadio más alto, dice Hegel:

El reino de los espíritus que de este modo [a través del recomenzar del espíritu cada vez de una etapa más alta] se forma en la existencia constituye una sucesión en la que uno ocupa el lugar del otro y cada uno de ellos asume del que le precede el reino del mundo. Su meta es la revelación de la profundidad y ésta es el concepto absoluto. ${ }^{38}$

Proponemos pensar una nueva forma de organización social que no esté fundada en el Estado ni en el Capital, a partir de esa revelación de la profundidad (die Offenbarung der Tiefe) del espíritu absoluto. Según esta interpretación (independientemente de lo que de ello pudiera pensar Hegel), habría en el «reino del mundo» una sucesión de organizaciones sociales, en etapas cada vez más altas (o quizás simplemente diferentes): el Estado, luego el capitalismo y más allá nuevas formas por venir, componiendo la escalera de Escher, siempre ascendente, el círculo que sólo es real por medio de su desarrollo. El espíritu no sería entonces la esencia del hombre, sino que el hombre encontraría en la

Así como Kojève se pronuncia en definitiva por el triunfo de la Riqueza en la dialéctica de la Fenomenología VI, B, Weil parece hacerlo por la del Estado.

38 Hegel, Fenomenología... op. cit., p. 473 (Phänomenologie, op. cit., p. 530). 
sucesión de los espíritus sus diversas formas de existencia. La Fenomenología así leída no sería ya una antropología filosófica sino una ontología (o al menos, una antropología que, en sus últimas páginas, abriría el paso a una ontología). Esto según la distinción entre antropología y ontología que realiza Deleuze leyendo a Hyppolite:

La filosofía deber ser una ontología, no puede ser otra cosa... Que la filosofía sea una ontología significará ante todo que no es una antropología... M. Hyppolite se eleva entonces contra toda interpretación antropológica o humanista de Hegel. El saber absoluto no es una reflexión del hombre, sino una reflexión del Absoluto en el hombre. ${ }^{39}$

Ya no una reflexión acerca del hombre, sino un reflejo del absoluto en el hombre. Quizás a partir de allí podamos revivir el gesto marxiano: «Lo más grande de la Fenomenología de Hegel y de su resultado final... es, por tanto, de una parte, el que Hegel conciba la autogénesis del hombre como un proceso». ${ }^{40}$ El hombre ya no es sujeto: abandona el centro y se coloca como efecto del proceso ontológico de determinación de formas existentes. El problema vuelve a ser entonces el de una antropología filosófica, pero en ruptura con la tradición iniciada por Scheler, ya que no se trata de una "reflexión sobre el hombre", sino de una "reflexión de lo absoluto en el hombre". La cuestión será a partir de este giro interpretar de qué manera el concepto absoluto interpela la forma en que el hombre se engendra a sí mismo en el proceso histórico de sucesión de «los espíritus». Para ello elegimos adentrarnos en los planteos antropológicos de Gilles Deleuze. El gesto parece casi irónico, ya que Deleuze ha sido uno de los principales adversarios de Hegel en general, y de su recuperación antropológica en particular ${ }^{41}$. Pero a partir de la cita que acabamos de reproducir (proveniente

39 G. Deleuze, «Jean Hyppolite, Logique et existence», en L'Ile déserte et autres textes. Paris: Minuit, 2002, pp. 18-21. La traducción es mía.

40 K. Marx, Manuscritos Económico-Filosóficos de 1844, en Escritos de Juventud, tr. W. Roces, México: Fondo de Cultura Económica, 1982, p. 650. «[Marx] propone sustituir el termino de hombre al término autoconciencia, y así desmitificar al hegelianismo. Esta sustitución transforma toda la filosofía hegeliana», Hyppolite, op. cit., p. 233. No podemos, por cuestiones de espacio, trabajar aquí la cuestión de la antropología marxiana de 1844, que sería objeto de otras confrontaciones (tras las fuertes críticas vertidas fundamentalmente por Althusser en la década del 60).

41 En el prefacio a Diferencia y repetición, Deleuze caracteriza a nuestro tiempo como «un anti-hegelianismo generalizado», $c f$. Deleuze, op. cit., p. 1. Y sus principales comentadores acuerdan en leerlo a partir de un contrapunto con Deleuze: «[Deleuze] no se enfrenta al hegelianismo para salvar sus elementos valiosos, ni para extraer "el corazón racional del caparazón místico", sino para articular una crítica total y un rechazo del marco negativo y así alcanzar una autonomía real, y una separación teórica, de toda la problemática hegeliana», M. Hardt, Gilles 
de uno de los primeros escritos publicados por Deleuze, en 1954, reseñando Lógica y existencia de Jean Hyppolite) avanzaremos hacia una interpretación de esos "espíritus» que conforman el Geisterreich en términos de concepto deleuziano de Ideas sociales. A través de ese sendero, buscaremos mostrar la posibilidad de una philia entre los pensamientos de Hegel y Deleuze, por fuera de la adversidad con la cual estos pensadores suelen presentarse.

\section{LA BÊTISE COMO ANIMALIDAD PROPIAMENTE HUMANA: EL FONDO SUBE A LA SUPERFICIE}

Se trata de pensar al hombre a partir de la noción de bêtise. «La bêtise es la bestialidad propiamente humana», ${ }^{42}$ dice Deleuze en Diferencia y repetición (publicado en 1968, precisamente el año de la segunda edición de la Introducción... de Kojève). Deleuze plantea lo que entiende como una pregunta propiamente trascendental: «icómo la bêtise -y no el error- es posible?». ${ }^{43}$ Quizás la bêtise nos ofrezca una alternativa a pensar el hombre como error y también a pensarlo como snob.

Para Deleuze, pensar al hombre como bêtise implica pensar una nueva relación con el fondo, con aquel Tiefe cuya revelación era para Hegel el concepto absoluto. Así logrará seguir los pasos de su maestro Hyppolite quien afirmó en Lógica y existencia que «el saber absoluto no es una antropología», ${ }^{44}$ sino que nos ofrece las condiciones (trascendentales) en las cuales el hombre será hombre. La bêtise no es una reflexión del hombre, sino del Absoluto en el hombre.

La individuación como tal, operando bajo todas las formas, no es separable de un fondo puro que hace surgir y que arrastra consigo. Es difícil describir este fondo, y a la vez el terror y la atracción que suscita. Remover el fondo es la ocupación más peligrosa, pero también la más tentadora... Pues este fondo, con el individuo, sube a la superficie y sin embargo no toma forma o figura. El está allí, y nos mira, pero sin ojos. El es lo indeterminado, pero en tanto que continúa abrazando la determinación, como la tierra al zapato... La bêtise no es el fondo ni el individuo, sino esa relación en la que la individuación hace subir el fondo sin poder darle forma. ${ }^{45}$

Deleuze, an Apprenticeship in Philosophy, Minneapolis: University of Minnesota Press, 1993, p. xi, La traducción es mía. «El ataque de Deleuze a la negatividad llega al corazón de la noción hegeliana de historia. Sin la idea del "trabajo del negativo", la historia para el hegeliano es apenas una serie azarosa de acontecimientos », Roth, op. cit., p. 196.

42 Deleuze, Différence... op. cit., p. 196.

43 Deleuze, op. cit., p. 197.

44 Hyppolite, op. cit., p. 233.

45 Deleuze, op. cit., p. 197 
Die Offenbarung der Tiefe implicaba justamente para Kojève una subida del fondo que acarreaba la disolución del hombre y de la historia. ${ }^{46}$ Esa subida es para Deleuze pura bêtise: un fondo que sube sin que se pueda darle forma. La "evolución" de Kojève entre 1939 y 1968 es en realidad una serie de estrategias con un mismo objetivo: protegerse de esa subida del fondo. Primero, en 1939, a través de una "solución final": la disolución del hombre "como error" en el espíritu absoluto. Pero Kojève asiste a la insistencia de la realidad sobre sus hipótesis: el hombre no es error, sino bêtise. El error puede ser eliminado, sin resto; la bêtise, en cambio, persiste, no puede suprimirse. Insiste. Nada nos protégé de la subida del fondo. Nada. El saber absoluto no es el fin de la historia, sino el advenimiento de un nuevo espíritu en el reino del mundo. En la profundidad, como concepto absoluto, se refleja una nueva figura del hombre: el que permanece en vida como un animal, feliz como los pájaros y las arañas. Plantea así en 1948 una segunda forma de protección del fondo: a través de la animalidad. «El animal está protegido [de la subida del fondo] por las formas específicas que le impiden ser "bestia"». ${ }^{47}$ Kojève no anula así la bêtise, sino que la considera «desde el punto de vista de la filosofía de la naturaleza». ${ }^{48}$

Pero el idilio dura poco. El hombre como animal es bestia, «bête intellectuelle» ${ }^{49}$ De pronto los pájaros y las arañas devienen monstruosos. «Todas las determinaciones devienen crueles y malvadas, no siendo captadas más que por un pensamiento que las contempla y las inventa, despellejadas, separadas de su forma viviente, flotando sobre ese fondo lúgubre». ${ }^{50}$

Una vez más, la incapacidad de Kojève de despegarse de la caracterización de lo humano que hereda de la antropología filosófica es la que lo arrastra hacia el callejón sin salida. De acuerdo a esa caracterización, el hombre parece como una determinación inmediata del Yo sobre la pasividad: «La determinación 'yo pienso' implica evidentemente algo indeterminado ('yo soy'), pero nada nos dice todavía cómo este indeterminado es determinable por el yo pienso»». ${ }^{51}$ Esa es la raíz de la ilusión antropológica, que en Scheler aparece como una forma (Espíritu) que se aplica directamente a un indeterminado (la vida). No hay mediación, nada nos dice Scheler acerca de «cómo este indeterminado es determinable». En estas condiciones, cuando lo determinado nos aparece como horroroso (por ejemplo el hombre derramando la sangre del hombre en

46 Cf. Kojève, op. cit., p. 440

47 Deleuze, op. cit., p. 196.

48 Deleuze, op. cit., p. 198.

49 Cf. Kojève, op. cit., p. 84.

50 Deleuze, op. cit., p. 198. «Desde el punto de vista de la filosofía de la naturaleza, la locura surge en el punto donde el individuo se refleja en ese fondo libre, y por consecuente, a continuación, la bêtise en la bêtise, la crueldad en la crueldad, y no puede ya soportarse», ibid.

51 Deleuze, op. cit., p. 116 
la guerra, por ejemplo el hombre sometido en el Estado despótico, por ejemplo el hombre pobre diablo luchando por su pellejo en el capitalismo) todas las determinaciones del hombre se vuelven crueles y malvadas: «el presentimiento de una fealdad propia del rostro humano, de una subida de la bêtise, de una deformación en el mal, de una reflexión en la locura». ${ }^{52}$

En la nota de 1968, en un último intento de protegerse del fondo, Kojève recurrió a la figura del snob como facultad de la pura forma. Buscaba recuperar la capacidad de la forma sin aceptar aún ese fondo que le seguía apareciendo como terrible. Pero «separadas de su forma viviente» esas formas flotaban sobre el fondo lúgubre, sin recuperar la posibilidad del hombre. Seguía reflexionando sobre el hombre, y no podía lanzarse al absoluto abierto por la profundidad. No hacía ontología. Sólo filosofía de la naturaleza hipostasiada.

Deleuze toma la distinción (tan hegeliana) entre filosofía de la naturaleza y filosofía del espíritu para superar el carácter lamentable de la bêtise. Porque ésta es lamentable en tanto «filosofía de naturaleza», pero se transforma «en la facultad real cuando anima la filosofía como filosofía del espiritu, es decir cuando induce a todas las facultades a ese ejercicio transcendente que hace posible la violenta reconciliación del individuo, del fondo y del pensamiento». ${ }^{53}$ Como en Hegel, en Deleuze la filosofía del espíritu implica una relación con el fondo (con el absoluto). Esa relación que Kojève, por no dejar de reflexionar sobre el hombre, fue incapaz de ver. Pero esta relación no implica necesariamente destrucción (aunque la destrucción es siempre un peligro), sino también como posibilidad de configurar nuevas formas de reconciliación, impensables previamente al contacto con el fondo al que nos ha lanzado la bêtise: un pensamiento (creación de Ideas) que sea la forma bajo la cual lo indeterminado (el fondo) es determinable (individuo).

\section{La FENOMENología COMO ONTOLOGÍA Y LA GÉNESIS dE LAS IdEAS}

Se trata de pensar cómo lo indeterminado es determinable por la determinación. Todo el rico campo de las mediaciones entre determinación e indeterminado, entre forma y fondo, recuperan la visibilidad perdida por la ilusión antropológica. La oposición entre espíritu y vida se disuelve, no a favor de uno de los polos, sino a favor de su articulación. Ese era el rol que Hegel había imaginado en su obra de madurez para la constitución del Estado: un sistema de mediación.

52 Deleuze, op. cit., p. 198.

53 Ibid. El subrayado es mío. 
Considerados como un órgano mediador, los estamentos están entre el gobierno por una parte y el pueblo, disuelto en sus esferas e individuos particulares, por otra... [Su función] impide que el poder del príncipe aparezca como un extremo aislado, y por lo tanto como mero poder arbitrario y dominador, y que evita también que se aíslen los intereses particulares de las comunidades, corporaciones e individuos, o, más aún, que los individuos se conviertan en una multitud [Menge], en un simple agregado [Haufens]... La constitución es esencialmente un sistema de mediación. En los Estados despóticos, en los que sólo existen los príncipes y el pueblo, si este último actúa, lo hace únicamente como masa destructora que se opone a la organización. En un sistema orgánico, en cambio, la multitud hace prevalecer sus intereses de modo que se adecua al derecho y al orden. ${ }^{54}$

El hombre no se encontraba inmediatamente determinado, ni subjetivamente por el yo pienso, ni socialmente por el monarca. El Estado ya no aparecía así como determinación despótica como en la Fenomenología, aplastando a lo determinado «como el zapato a la tierra». ${ }^{55}$ Como señalaba Weil: «No es el Estado, hoy amo del hombre, al que pertenece el porvenir, sino al hombre que será hombre, no a pesar del Estado sino en el Estado». ${ }^{56}$ Con la mediación, el hombre es un reflejo del absoluto (mientras la mera reflexión sobre el hombre arrasa con todas las mediaciones). El problema es que el Estado, como mediación, no nos protege del despotismo, ya que es una mediación despótica. Y esto más allá de que tenga en el «reino del mundo» la forma de Prusia, o una «nueva forma que se anuncia». Es necesariamente despótica en tanto se trata de la encarnación, única posible, de la Idea hegeliana, única possible (tal como es expuesta en la Ciencia de la lógica). Para Weil, el surgimiento del Estado será la defensa final de la teoría hegeliana: «Hegel no tiene necesidad de defensores; si su teoría es justa, la realidad misma se encargará de justificarla». ${ }^{57}$ Valgan la guerra y la sangre, si son necesarios para su implementación. Y esto ocurre por la necesidad de la Idea tal como el sistema de madurez de Hegel la había postulado:

Los monarcas no se distinguen por su fuerza corporal ni por el espíritu, y sin embargo millones se dejan dominar por ellos. Ahora bien, es absurdo decir que los hombres se dejan gobernar contra sus intereses, fines y propósitos, pues no son tan tontos; es su propia necesidad, es el poder interno de la idea, lo que los

54 Hegel, Principios... op. cit., pp. 453-545 (Grundlinien, op. cit., pp. 471-472).

55 «[El individuo] es lo indeterminado, pero en tanto continúa abrazando la determinación, como la tierra al zapato», Deleuze, op. cit., p. 197.

56 Weil, op. cit., p. 131.

57 Weil, op.cit., p. 9. 
obliga, incluso contra su conciencia aparente, y los mantiene en esta relación [Verhältnis]. ${ }^{58}$

La bêtise marca el punto en que la subida del fondo derroca toda tiranía: la del Estado y la de la Idea: «El tirano institucionaliza la bêtise pero es el primer siervo de su sistema, y el primer instituido, es siempre un esclavo el que comanda a los esclavos». ${ }^{59}$ La bêtise invierte las condiciones de la determinación de los viejos sistemas de representación. Ya no es el tirano (la determinación) el que controla el sistema, sino el siervo de un loco sistema controlado por la subida del fondo. La multitud toma el poder. La tierra atrapa al zapato. La anarquía se asoma. ¡O desesperación! ¿Tendría razón Weil? ¿Sólo el Estado puede salvarnos? Pero es demasiado tarde para él. He allí el logro de la bêtise: insistir, persistir. No dejarse echar a un lado.

Sólo queda el otro camino. Fuerza del reino de los espíritus (Geisterreich) decía Hegel. Facultad «real» cuando anima «la filosofía como filosofía del espíritu», decía Deleuze. La inspiración es común: se trata de transformar la facultad lamentable en facultad «real» De pasar de la filosofía de la naturaleza a la del espíritu. De pensar el Geisterreich. Y así superar el Estado y el Mercado hacia un höherer Stufe. Inducir «todas las facultades a ese ejercicio trascendente que hace posible la violenta reconciliación el individuo, del fondo y el pensamiento». ${ }^{60}$ ¿Cuál es esa reconciliación?: la creación de Ideas. Gracias a la bêtise como facultad la Idea ya no es despótica y el Estado ya no aparece como la única determinación capaz de mantener al hombre en la existencia. El Mercado ya no aparece como la única opción libertaria. Estado y Mercado no aparecen ya como dos polos en conflicto, sino como dos formas posibles de determinar lo indeterminado: dos Ideas sociales. Lo cual abre el campo a la posibilidad de nuevas articulaciones: nuevas Ideas como «sistema de ligazones múltiples ideales, o de relaciones [rapports] diferenciales entre elementos diferenciales». ${ }^{61}$ La idea no los mantiene bajo una relación [in diseem Verhältnis erhält] sino que es un sistema de relaciones diferenciales [système de rapports diffiférentiels]: carácter netamente creativo de la ontología. Una de las clases de Ideas que Deleuze analiza es justamente la Idea social:

Las condiciones económicas del problema [Idea] determinan o engendran la manera en la que éste encuentra sus soluciones en el marco de las relaciones reales de una sociedad, sin que el observador pueda de allí extraer el menor optimismo, ya

58 Hegel, Principios... op. cit., p. 433 (Grundlinien, op. cit., pp. 453-454).

59 Deleuze, op. cit., p. 196.

60 Deleuze, op. cit., p. 198.

61 Deleuze, op. cit., p. 240. 
que estas «soluciones» pueden tener la bêtise y la crueldad, el horror de la guerra $\mathrm{o}$ «la solución del problema judío». ${ }^{62}$

Las Ideas sociales se encarnan en sus casos de solución (el reino de los espíritus en el reino del mundo). Estas soluciones no son necesariamente buenas. La guerra, el capitalismo, el despotismo, son todas soluciones posibles. Pero atravesando todas las soluciones, algo propiamente humano: la bêtise, que tiene el singular mérito de conducirnos al campo de génesis de las Ideas (el fondo). $\mathrm{Y}$ a partir de ese absoluto, pensar al hombre como un reflejo, como figura. Si se trata de pensar una ontología donde el absoluto se refleje en el hombre (sin aniquilarlo ni aplastarlo, merced a un rico mecanismo de mediaciones), en ciclos siempre renovados, en estadios siempre más elevados, creo que, al menos en este punto, aparecería la philia de Hegel y Deleuze. El pensador francés no admitió que existiera una sola Idea pero, como su colega alemán, nunca dejó de pensar en la posibilidad de un contacto con el fondo que nos permita salir de esta ceguera del mundo que nos es contemporáneo, donde parecemos haber sido arrojados a la vida y el azar de los encuentros.

Julí́n FerReyra es investigador de la Comisión Nacional de Investigaciones Científicas y Tecnologías de Argentina (Conicet), docente de Antropología Filosófica (UBA).

\section{Publicaciones recientes:}

2010: L'ontologie du capitalisme chez Gilles Deleuze, Paris: L'Harmattan.

2010: "Deleuze, Strauss y una brecha en medio de Spinoza", Isegoría, Revista de filosofía moral y política, $\mathrm{N}^{\mathrm{o}} 42$.

Línea de investigación:

Antropología filosófica, ontología y filosofía política en Deleuze y Hegel.

\section{Dirección electrónica:}

djulianferreyra@gmail.com

62 Deleuze, op. cit., p. 241. 